\title{
Review
}

DOI: $10.21276 /$ ijchmr.2016.2.2.11

\section{Behavioral Screening Tests to Detect Hearing Loss in School Aged Children: A Review \\ Ratul Dey ${ }^{1}$, Jai Lal Davessar ${ }^{2}$, Satish Kumar $^{1}{ }^{1}$ Tijender Sharma $^{3}$}

${ }^{1}$ Lecturer, ${ }^{2}$ Professor \& Head, ${ }^{3}$ Audiologist and SLP, Department of ENT, Guru Gobind Singh Medical College, Faridkot.

\begin{abstract}
Hearing impairment, if not identified early in life can lead to affected social, emotional, behavioural and cognitive spheres of any child. Alarming incidence and prevalence of hearing impairment among young school aged children have been reported. This article reviews various behavioural screening tests to detect presence of hearing loss. Hearing screening tests have been designed using pure tones, speech stimulus, questionnaires, checklists etc. All of these procedures were administered either individualized or in groups. Screening with pure tones has been preferred over those which incorporated speech stimuli. This choice was because the latter was flawed by troublesome maintenance and difficult response patterns. Individualized screening designs were found to be easier and more comprehensive by many authors. With the advent of newer technologies many objective tests have been introduced which are more competent in identifying hearing loss. Since many parts of the country is still lacking adequate infrastructure and experienced audiologists, as of date, it is worth realizing the importance of behavioural screening hearing tests.
\end{abstract}

Keywords: Hearing loss; Audiometry; Screening

Corresponding author: Ratul Dey,Lecturer,Department of ENT, Guru Gobind Singh Medical College, Faridkot.Email-deysworld@gmail.com

This article may be cited as:Dey R,Davessar JL,Kumar S and Sharma T.Behavioral Screening Tests to Detect Hearing Loss in School Aged Children: A Review.Int J Com Health and Med Res 2016;2(2):73-79

Article Received: 03-05-2016

Accepted On: 12-05-2016

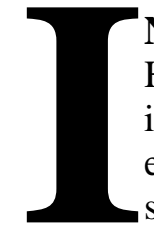

\section{NTRODUCTION}

Hearing impairment, if not identified early in life can lead to affected social, emotional, behavioural and cognitive spheres of any child. ${ }^{1}$ The prevalence of hearing loss in school going children ranges from $5.7 \%$ (NSSO, 1991) to as high as 12 $\% .^{2}$ Though rural population has been found to be more affected as compared to urban, the incidence and prevalence of both are alarming. Identifying hearing loss as early as possible is important for better intervention. ${ }^{3}$ This article is aimed to review various behavioural hearing screening tests advocated to be efficient in detection of hearing loss.

\section{Screening with pure tones}

Many researchers suggested pure tones as a screening tool. Some used it for group screening programme ${ }^{4,5}$ and few for individual screening. ${ }^{2,6,}$

\section{Group Hearing Tests}

Group hearing tests were developed for mass screening purpose especially among school-going children. These tests were preferred due to lesser time consumption. ${ }^{4,9}$

\section{Pulse Tone Group Test}

Developed by Reger and Newby ${ }^{4}$, the test started at $40 \mathrm{~dB}$ and decreased in 10 and $5 \mathrm{~dB}$ steps. Each frequency was tested in this descending method to determine the threshold. 40 children could be tested at a time with this test. The children were required to respond by marking the appropriate number of tones heard by them at each frequency. Strenget al. ${ }^{10}$ opined that though this test could be successfully used to screen adult or college going 
students, it was difficult to administer it on school age children. Hollien and Thompson ${ }^{11}$ developed another pulse tone test after the Reger-Newby test. Children had to mark digits written on an answer sheet as they hear and count the number of presentations.

\section{The Massachusetts Hearing Test}

During World War II, the need was felt for more valid group hearing screening tests which could better correlate with discrete frequency hearing tests. Johnston ${ }^{12}$ developed a test that utilized an audiometer with 10 to 40 receivers, depending on the number of students. The use of this test was discontinued chiefly because of its limitations such as use of limited frequencies $(512 \mathrm{~Hz}, 1024 \mathrm{~Hz}$, $4096 \mathrm{~Hz} \& 11584 \mathrm{kHz}$ ).

\section{Johnston group screening test}

Addressing the limitations of the Massachusetts Hearing Test such as testing of limited band of frequencies, Johnston ${ }^{4}$ modified the test with use of a wide band of frequencies (125 cps to 6000 cps) and an easier response pattern (without use of pencil and paper) for the children. These addressed a few of the major limitations of the earlier tests. However, this modification could not bring the test a wide acceptance in schools because of affordability issues. American Speech and Hearing Association (ASHA) ${ }^{13}$ reported several disadvantages of group screening tests including requiring written responses from children, troublesome calibration of the audiometric system because of multiple receivers involved and increased number of false positives. This reduced the popularity of group tests and individualized hearing screening programmes were thought necessary.

\section{Individual Hearing Screening}

Individualized hearing screening tests, at the beginning, involved administration of subjective tests such as whispered and spoken voice tests and watch and coin click tests. These tests were primarily designed for screening military personnel and to be used at physicians' clinics where facility of pure-tone audiometry was not available. However, Newby ${ }^{14}$ recommended that such tests could also be used with children for screening purpose. He reported that these tests were meant to test specific frequencies. The watch tick was meant to assess low frequency sound perception and the coin click high frequency sound perception. The sound was made from a distance and the person was asked about its audibility. A person who was able to hear the click of a watch from a distance that a normal hearing person could hear it was considered to have normal hearing.
The coin click test was developed primarily to check high frequency hearing. The coin was dropped on a metal surface and the patient was asked to describe the kind of sound he heard. The subject was assumed to have normal hearing in that range if he could hear a 'ping'. However, if a dull sound was reported, he was considered to have some amount of loss at that range of frequencies. Earlier, Miller and Polisar ${ }^{15}$ opined that, it was able to test only a limited range of frequencies. The efficacy of such a test, therefore, was highly questionable and lead to high clinician and environment variability. In view of these disadvantages, individual hearing screening tests involving the use of pure-tones were advocated..$^{7,8}$ 14; 16-21. Different frequency and / or combination of frequencies were suggested by various researchers. The use of a single frequency $(4 \mathrm{kHz})$ for hearing screening was suggested by Glorig and House. ${ }^{16}$ They compared the results of the single frequency screening procedure and the conventional 'sweep' test. The latter test was described by Newby ${ }^{14}$ to be one of the early individual hearing screening tests for children designed to obtain quick responses. This test involved successive presentation of pure-tones from an audiometer at a fixed level of 20 or $25 \mathrm{~dB}$ that sweep through the test frequencies $(250 \mathrm{~Hz}$ through $8 \mathrm{kHz})$, usually from low to high in order. Glorig and House ${ }^{16}$ found that there was $98.5 \%$ agreement between the two tests. This suggested that screening at only $4 \mathrm{kHz}$ could be as good as a sweep frequency test up to 6 frequencies. Also, they found that threshold at $4 \mathrm{kHz}$ was equal to or more than the thresholds at other frequencies. Therefore, they opined that testing only at $4 \mathrm{kHz}$ served the purpose of a successful screening. The other advantages of the test was that it was a quick measure of hearing sensitivity, cost effective and good to use in the paediatric population since it required lesser time and therefore taxed the attention of the children to a lesser extent. They carried out the screening using an instrument called 'Oto-Chek' which had 2 different modules: one for only $4 \mathrm{kHz}$ and one for double frequency testing ( $2 \mathrm{kHz} \& 4 \mathrm{kHz})$. Lightfoot, Buckinghum and Kelly ${ }^{22}$ criticised the House-Glorig test as they found that 30 to $35 \%$ of the impaired population including those with unilateral or bilateral hearing loss went undetected. Most of these children had secretory otitis media, impacted cerumen and chronic otitis media. Hence, they suggested the use of screening at $2 \mathrm{kHz}$ and $4 \mathrm{kHz}$ periodically only in the condition where the audiologist has an idea about the optimal thresholds at other 
frequencies.Miller and Bella ${ }^{6}$ found that $4 \mathrm{kHz}$ was not the frequency with greatest amount of loss in a large number of children. With the use of this frequency alone, only $39 \%$ of cases with medically significant hearing loss were identified.They suggested a combination of $1 \mathrm{kHz}$, $2 \mathrm{kHz}$ and $4 \mathrm{kHz}$ and found that the detection of hearing loss was no worse when compared to regular 5 frequency testing. In search of the best possible means to screening, Lawrence and Rubin $^{18}$ employed different combination of frequencies in order to check their efficacy. Their findings suggest only $60 \%$ to $70 \%$ agreement of the $4000 \mathrm{~Hz}$ test with the sweep tone test. Whereas the agreement was $76 \%, 90 \%$ and as high as $95 \%$ when combinations of $4000 \mathrm{~Hz}$ \& $2000 \mathrm{~Hz}, 4000 \mathrm{~Hz}$ \& $500 \mathrm{~Hz}$ and octave frequencies from $500 \mathrm{~Hz}$ through $4000 \mathrm{~Hz}$ were employed respectively. Therefore, they concluded that a combination of $4000 \mathrm{~Hz}$ and $500 \mathrm{~Hz}$ was the best reasonable option. In 1997, ASHA $^{23}$ continued the recommendation of testing at 3 frequencies, however changed the frequencies to $1 \mathrm{kHz}, 2 \mathrm{kHz}$ and $4 \mathrm{kHz}$ at $20 \mathrm{~dB} \mathrm{HL}$ with at least 2 presentations. To obtain the responses, the use of conventional audiometry or conditioned play audiometry was suggested. The guidelines also suggested avoiding the use of any stimulus which was not frequency specific such as speech, music or broadband noise. For school-going children, ASHA recommended compulsory periodical screening at $3^{\text {rd }}, 7^{\text {th }}$ and $11^{\text {th }}$ grade. The protocol involved pure-tone screening as it is recommended for the previous group. Later, Bess, et al. ${ }^{2}$ also suggested not using nonconventional instruments, as they produce high false positive rates. In India, Nikam and Dharamraj ${ }^{8}$ conducted a school screening programme using pure-tones of $500 \mathrm{~Hz}$, $1 \mathrm{kHz}, 2 \mathrm{kHz}$ and $4 \mathrm{kHz}$ at 30,20, 20 and $20 \mathrm{~dB}$ (ref, ISO) respectively. They evaluated 2086 children in the age range of 2 to 14 years from 12 different schools. Their findings revealed a large number of false positives $(67.6 \%)$ when the screening results were compared with diagnostic pure-tone audiometry. The authors attributed this to either high ambient noise masking the test tone or due to the stringent criteria for failure or both. However, they suggested the use of $250 \mathrm{~Hz}$, considering the fact that children in the age group tested by them usually had low frequency conductive hearing loss due to common middle ear disorders. Kapur ${ }^{7}$ evaluated 1084 school-going children using pure-tone audiometry. The prevalence of hearing loss was found to range from $16.3 \%$ to $18.6 \%$. The screening programme missed out $3.7 \%, 5 \%$ and $3.4 \%$ of the children from three different schools who had conductive hearing loss. This was determined after comparing the results of the screening audiometry to that of the diagnostic pure-tone audiometry. Despite puretones being recommended for hearing screening programmes by several authors, a few studies have also employed speech as screening material. ${ }^{24,25}$ However, the use of speech material for hearing screening is relatively sparse compared to the use of pure-tones.

\section{Screening tests using speech material}

Pre-school or school age children have been noted to not respond to pure tones as effectively as speech material (Martin, 1991). ${ }^{26}$ Therefore, the use of speech material has been found to be advantageous for this age group. In literature a few researchers ${ }^{24,25}$ have emphasized on the use of speech material for hearing screening purpose.

\section{Verbal Auditory Screening for Children}

Griffing et al. ${ }^{25}$ developed a procedure called Verbal Auditory Screening for Children (VASC). It was developed with the objective of having a reliable method of hearing screening in the preschool age group. They used spondaic words as stimulus and a picture identification task to obtain responses. The referral rate of the screening test was $10 \%$ which was found to be consistent with the prevalence of hearing loss. However, no comparison of the data was made with pure-tone thresholds of the children. The disadvantage of the use of speech stimuli as material for screening was that it resulted in a large number of false negatives. Ritchie and Merklein ${ }^{27}$ investigated the efficacy of VASC and they found that it misses $48.8 \%$ of children with hearing impairment which was almost equal to the number it was able to correctly identify. Melcher \& McCulloch ${ }^{28}$ attributed this to the audibility of some high intensity phonemes in some of the words which could yield cues to the child with a mild hearing loss limited to certain frequencies, thus resulting in a positive response and therefore reducing the sensitivity of the screening test. In their study, Mencher and $\mathrm{McCulloch}^{28}$ found that VASC failed to identify hearing losses of 30 to $40 \mathrm{~dB}^{29}$ (ref. ANSI, 1969) in the speech frequency range and of 30 to $50 \mathrm{~dB}$ in the high frequency $(4-6 \mathrm{kHz})$ range. Therefore, they opined that the choice of test should be depending upon the test purpose. If screening was to identify severe hearing losses, VASC may be an acceptable method for obtaining information. However, if the intent was to identify even subtle 
difficulty in hearing, VASC should not be recommended.

\section{Whispered and Spoken Voice Tests}

The test involved the presentation of spondees from a distance of 20,15, 10, 5, 2 and 1 foot at conversational level. Responses were noted in terms of a denominator over a numerator 20 where 20/20 indicates normal hearing and 5/20 indicates approximately $5 / 20^{\text {th }}$ hearing ability of a normal. This test appeared to be advantageous because of ease of administration, lesser expense and the use of functional stimuli. However, these advantages were outweighed by the limitations such as lack of control of the sound source, speaker and environment variability, lack of standardization of material, failure to test wide frequency range and most importantly failure to acquire ear-specific response. Glorig ${ }^{30}$ compared the findings of the whispered voice test with calibrated speech audiometry and found high inconsistency in the results of the screening test. It was concluded that the spoken voice test has inherent fault which made it impossible to arrive at even approximate hearing thresholds. Earlier, Fowler ${ }^{31}$ had opined that voice reflex was a source of inaccuracy in conversational speech tests. As the distance from the subject increased, the voice was made louder. This increment was undoubtedly different in different speakers. Therefore, the high clinician variability that was encountered in administering the test made it undesirable.

\section{Verbal Audiometric test}

Speech material has also been reported to be used in a group test developed by Meyerson. ${ }^{24}$ The test was designed to be used among two groups: preschool to primary grade children and children of $4^{\text {th }}$ to $12^{\text {th }}$ grade. Words with spondaic stress pattern were selected. Selection of the words involved consideration of their audibility, familiarity to the target group of children and speech sound distribution. Each test form consisted of 3 parallel series of 12 stimulus words. Each stimulus word was preceded by a 3 -word carrier phrase. The preschool and primary grade children responded through picture identification and written responses were attained from the elder age group children. Meyerson reported that the test had very good reliability. The use of speech material for the purpose of screening has been criticised in literature. The criticism has been primarily due to the lack of control in the presentation of the speech stimuli. This lack of control led to speech material being considered as ineffective in identifying hearing impairment.

\section{Screening with Ling sounds}

Efficiency of Ling speech sounds as a screening tool was assayed by Dey and Yathiraj. ${ }^{32}$ Ling sounds were presented to childrens' ears through TDH 49 headphones from a laptop. They found sensitivity specificity of the recorded Ling speech sound test to be $82 \%$ and specificity $90 \%$ respectively. Use of hearing screening checklist did not improve the results by any significant factor. They advocated the use of recorded Ling sound test for school screening programmes. The selection was also made as it involved simple instrumentation and easy operation.

\section{Screening Programs using checklists or questionnaires}

Checklists or questionnaires have been reported to be used to identify hearing impairment and their impact on communication. Such questionnaires have been used more with adults ${ }^{33}$ or with infants. ${ }^{34}$ Relatively few questionnaires have been used for identifying hearing problems in schoolgoing children. ${ }^{32,35,36}$ These checklists are reported to be answered by the parents or the school teacher. $^{36-39}$ Also, few studies ${ }^{35,36}$ have involved teachers and parents referring the children followed by verbal training given to them. The few studies that have used screening checklists to detect hearing problems in school children are discussed below.

\section{Use of checklists by teachers}

The use of checklists by teachers to detect hearing problems has been utilised since several decades. One such attempt was carried out by Kumar and D'Mello ${ }^{36}$ where they used a questionnaire to detect hearing loss to be answered by school teachers. Using the questionnaire that had 9 questions, 6591 children were screened. The first 8 questions included information related to oro-facial deformity, middle ear infections, foreign body in the ears, symptoms of conductive hearing loss, poor attention, unilateral hearing problems and speech problems such as, misarticulation, stuttering etc. The last question was an open ended question to identify presence of any other kind of disability such as mental retardation, autism etc. The results of the study revealed that $15.96 \%$ of the children were identified at-risk for hearing loss.Another study was conducted by Dey\& Yathiraj $^{32}$ to find how good a checklist is to identify hearing difficulties in school children. They found poor efficiency of the checklist where it has sensitivity and specificity of only $49 \%$ and $76 \%$ only. Hence they did not recommend use of checklist in identifying hearing loss. 


\section{Use of questionnaires by parents}

In literature, there are studies which involved parents in answering questionnaires $n 63$ to symptoms of hearing loss. ${ }^{37-39}$ These 63 mies suggested poor parental efficiency in detecting presence of hearing loss in children aged 5 to 7 years. Olusanya ${ }^{37}$ interviewed parents of 359 school-going children (mean age of 6.7 years) based on a structured questionnaire. The questionnaire incorporated the past medical or developmental history of the children and their family. It was found that, the questionnaire had a very poor sensitivity $(10 \%)$ and a high specificity (94\%). However, the authors did not provide the questionnaire used in the study.In a similar kind of study, Gomes and Lichtig ${ }^{38}$ analysed the responses of parents regarding hearing impairment in their wards. Seven women employees of a local nursery school were trained and familiarized with the parent report questionnaire in order to enable them to use the instrument with the parents of the children. The results showed that the volunteers could reproduce the evaluation of the researcher and the accordance was at least $77 \%$. However, the questionnaire performed poor in differentiating the children who had failed the audiological evaluation from those who did not. To determine the efficacy of a questionnaire in identifying middle ear pathologies in 5898 children of 6 to 7 years of age, Lo et al. ${ }^{39}$ carried out a study. A selfadministered medical history questionnaire was sent through the schools to the parents. In addition, a binary choice question was made asking whether or not there was a suspicion of hearing impairment in the child. Based on the questionnaire, the parents had to bring their children to audiology clinics. The authors found a sensitivity of only $19.7 \%$ and a specificity of 96.9 $\%$. However, the positive predictive value (PPV) and negative predictive value (NPV) were determined to be $82 \%$ and $62.1 \%$ respectively.Use of medical questionnaires to identify hearing problems has also been reported in literature to be used for screening for hearing loss in children. Gerwin and Read ${ }^{40}$ investigated the prediction of hearing loss using a medical questionnaire which consisted of 40 questions. The questionnaire was different from physicians' history in that it was not administered by the physician. Also, the questionnaire differed in terms of the questions included which had a great deal to do with prenatal and post natal medical history. The parents were asked to answer the questionnaire. Of the 40 questions a few were directly relevant to hearing loss and a few were not. The researchers found that only a few of the questions were found to detect the actual presence of hearing loss.

\section{CONCLUSION}

Widely varying opinions are available in the literature regarding the choice of tools / tests for hearing screening in children. In modern practice many objective procedures are employed which is not discussed as those do not come under scope of the present article. However objective screening is expensive and requires professional services and expertise. Rural parts of India where adequate infrastructure and professional services are compromised, any one or a combination of the behavioural procedures which make reasonably fair referral can be worth administering.

\section{REFERENCES}

1. Yoshinaga-Itano C, Sedey A, Coulter D, Mehl A. Language of early and later identified children with hearing loss. Paediatrics 1998; 102(5): 1161-1171.

2. Bess FH, Dodd-Murphy J, Parker R. Children with Minimal Sensorineural Hearing Loss- Prevalence, Educational performance \& Functional Status. Ear and Hearing 1998; 19: 339-354.

3. Maxon $A B$, Brackett D. Mainstreaming Hearing Impaired Children. In: Bradford LJ, Martin FN, Eds. Audiology- An Audio Journal for Continuing Education. $6^{\text {th }}$ ed. New York: Grune and Stratton Inc; 1981.

4. Reger SN, Newby HA. A Group PureTone Hearing Test. Journal of Speech and Hearing Disorders 1947; 12: 61-66.

5. Johnston PW. An Efficient Group Screening Test. Journal of the Acoustical Society of America 1952; 17: 8-12.

6. Miller MH, Bella JL. Limitations of Selected Frequency Audiometry in the Public Schools. Journal of Speech and Hearing Disorders 1959; 24: 402-407.

7. Kapur YP. A Study of Hearing Loss in School Children in India. Journal of Speech and Hearing Disorders 1965; 30: 225-233.

8. Nikam S, Dharamraj. School screening programme in Mysore city. Journal of All India Institute of Speech and Hearing 1971; 1: 28-32.

9. Neilsen SF. Group Testing of School Children by Pure Tone Audiometry. Journal of Speech and Hearing Disorders 1952; 17: 4-7. 
10. Streng A, Fitch WJ, Hedgecock LD, Phillips JW, Carrell JA. Audiometry and Case finding. In: Hearing Therapy for Children, $2^{\text {nd }}$ ed. New York: Grune\& Stratton, Inc; 1958. p. 51-73.

11. Hollien H, Thompson CL. A group Screening Test of Hearing. Journal of Auditory Research 1967; 7: 85-92.

12. Johnston PW. The Masschusetts Hearing Test. Journal of the Acoustical Society of America 1948; 20: 697-703.

13. American Speech and Hearing Association. Guidelines for Identification Audiometry. Washington DC: American Speech and Hearing Association; 1975.

14. Newby HA. Public School Hearing Conservation Programs. In: Audiology, $4^{\text {th }}$ ed. New Jersy: Prentice-Hall, Inc; 1972. p. 306-307.

15. Miller MH, Polisar IA. Screening the Hearing of Young Children. In: Charles CT, editor. Audiological evaluation of the Pediatric Patient. Springfield, U.S.A; 1964. P: 92-96.

16. Glorig A, House HP. A new concept of auditory screening. American Medical Association: Archives of Otolaryngology 1957; 66: 228-232.

17. Hanley CN, Gaddie BG. The Use of Single Frequency Audiometry in the Screening of School Children. Journal of Speech and Hearing Disorders 1962; 27: 258-264.

18. Lawrence CF, Rubin W. The efficacy of Limited Frequency Audiometric Screening in a School Hearing Conservation Program. American Medical Association: Archives of Otolaryngology 1959; 69: 606-611.

19. FizZaland RE, Zink GD. A Comparative Study of Hearing Screening Procedures. Ear and Hearing 1984; 5(4): 205-210.

20. Manjula P, Jayaprakash E, Jayaram M. Hearing Screening in School-Going Children. Journal of the Indian Speech and Hearing Association 2002; 16: 40-46.

21. Sarafraz M, Ahmadi K. A practical screening model for hearing loss in Iranian school-aged children. World Journal of Pediatrics 2009; 5(1): 46-50.

22. Lightfoot C, Buckinghum A, Kelly MN. A check on Oto-chek. American Medical Association: Archives of Otolaryngology 1959; 70(1): 103-123.

23. American Speech-Language-Hearing Association. Guidelines for audiologic screening: Panel on audiologic assessment. Rockville MD: American SpeechLanguage-Hearing Association; 1997.

24. Meyerson L. Hearing for Speech in Children: A Verbal Audiometric Test. ActaOtolaryngologica 1956; Suppl. 128: 1-165.

25. Griffing TS, Simonton KM, Hegdecock LD. Auditory Verbal Screening for Children. Minnesotta Medicine 1962; 45: 35-36.

26. Martin FN. Introduction to Audiology. New Jersy: Prentice-Hall Inc; 1991. p. 395.

27. Ritchie B, Merklein R. An evaluation of the efficiency of the verbal auditory screening for children (VASC). Journal of Speech and Hearing Research 1972; 15: 280-286.

28. Mencher GT, McCulloch BF. Auditory screening of kindergarten children using VASC. Journal of Speech and Hearing Disorders 1970; 35: 241-247.

29. American National Standards Institute. Specifications for audiometers. (ANSI S3.6-1969). New York: American National Standards Institute; 1969.

30. Glorig A. Hearing evaluation by low conversational voice tests. Annals of Otology, Rhinology and Laryngology 1949; 58: 394.

31. Fowler EP. Discovery and evaluation of otic cripples. Archives of Otolaryngology 1947; 45: 550.

32. Dey R, Yathiraj A. Efficacy of a Hearing Checklist and Screening Test in Identifying Hearing Problems in Primary School Children. Student Research at A.I.I.S.H. Mysore (Articles based on dissertations done at AIISH) 2012; 10 : 225-233.

33. Sindhusake D, Mitchell P, Smith W, Golding M, Newall P, Hartley D, Rubin G. Validation of self-reported hearing loss. The blue mountain hearing study. International Journal of Epidemiology 2001; 30(6): 1371-1378.

34. Hayes D. State Programmes for Universal Newborn Hearing Screening. Pediatric Clinics of North America 1999; 46(1): 8994.

35. Curry ET. The Effciency of Teacher Referrals in a School Hearing Testing Program. Journal of Speech and Hearing Disorders 1950; 15: 211-214. 
36. Kumar S, D’Mello J. Identifying Children At-Risk for Speech and Hearing Disorders- A Preliminary Survey Report from Hyderabad, India. Asia Pacific Disability Rehabilitation Journal 2006; 17(2): 101-108.

37. Olusanya B. Early detection of Hearing Impairment in a Developing Country: What Options? Audiology 2001; 40: 141147.

38. Gomes M, Lichtig I. Evaluation of the use of a questionnaire by non-specialists to detect hearing loss in preschool Brazilian children. International Journal of
Rehabilitation Research 2005; 28(2): 171-174.

39. Lo P, Tong M, Wong E, Hasselt CV. Parental suspicion of hearing loss in children with otitis media with effusion. European Journal of Pediatrics 2006; 165(12): 851-857.

40. Gerwin KS, Read CB. Use of Medical Questionnaire to Identify Hearing Loss. In: Gerwin KS, Glorig A. (Eds.). Detection of hearing loss and ear disease in children. Springfield IL: Charles C. Thomas; 1974. p. 124-135.

Source of support: Nil

Conflict of interest: None declared

This work is licensed under CC BY: Creative Commons Attribution 4.0 License. 